\title{
Television viewing in Thai infants and toddlers: impacts to language development and parental perceptions
} Nichara Ruangdaraganon*1, Jariya Chuthapisith ${ }^{1,2}$, Ladda Mo-suwan ${ }^{3}$, Suntree Kriweradechachai ${ }^{1}$, Umaporn Udomsubpayakul ${ }^{4}$ and Chanpen Choprapawon 5

\author{
Address: ${ }^{1}$ Department of Paediatrics, Faculty of Medicine Ramathibodi Hospital, Mahidol University, Bangkok, Thailand, ${ }^{2}$ School of Community \\ Health Sciences, University of Nottingham, Nottingham, UK, ${ }^{3}$ Department of Paediatrics, Prince of Songkla University, Songkhla, Thailand, \\ ${ }^{4}$ Department of Research Centre, Faculty of Medicine Ramathibodi Hospital, Mahidol University, Bangkok, Thailand and ${ }^{5} \mathrm{Health}$ System Research \\ Institute, Ministry of Public Health, Nontaburi, Thailand \\ Email: Nichara Ruangdaraganon* - kositprapa@hotmail.com; Jariya Chuthapisith - mcxjc5@nottingham.ac.uk; Ladda Mo- \\ suwan - ladda.m@psu.ac.th; Suntree Kriweradechachai - suntreekrai@hotmail.com; Umaporn Udomsubpayakul - rauub@mahidol.ac.th; \\ Chanpen Choprapawon - cchopra2004@gmail.com \\ * Corresponding author
}

Published: 22 May 2009

BMC Pediatrics 2009, 9:34 doi:10.1 |86/147|-2431-9-34
Received: 27 June 2008

Accepted: 22 May 2009

This article is available from: http://www.biomedcentral.com/I47I-243I/9/34

(C) 2009 Ruangdaraganon et al; licensee BioMed Central Ltd.

This is an Open Access article distributed under the terms of the Creative Commons Attribution License (http://creativecommons.org/licenses/by/2.0), which permits unrestricted use, distribution, and reproduction in any medium, provided the original work is properly cited.

\begin{abstract}
Background: Effects of television to language development in infants and toddlers, especially in the Asian children, are inconclusive. This study aimed to (a) study time spent on television in Thai infants and toddlers (age $<2$ years), (b) investigate the association between time spent on television (as recommended by the American Academy of Paediatrics (AAP), $<2$ hours per day) and language development in Thai 2-year-old children, and (c) explore parental perceptions on television toward their child's development.
\end{abstract}

Methods: Two hundred and sixty children and their parents were recruited into the study. Time spent on television and parental perceptions on television viewing toward their child's development were recorded during face-to-face and telephone interviews. Language development was assessed at the age of 2 years using the Clinical Linguistic Auditory Milestone Scale (CLAMS), and parents' report. Association between delayed language development and time spent on television viewing, as well as other various parameters such as gender, maternal education and family income, were analysed using a multivariate logistic regression model.

Results: Most Thai infants and toddlers watched television at the age of 6 months, I year and 2 years old (98.0, 95.3 and $96.7 \%$, respectively). On average, I-year-old children watched television $1.23 \pm 1.42$ hours per day. This increased to $1.69 \pm 1.56$ hours per day when they were 2 years old. However, watching television longer than 2 hours per day did not associate with delayed language development. On multivariate logistic regression analysis, gender (male) was the only significant factor associated with delayed language development $(\mathrm{OR}=6.9,95 \% \mathrm{Cl}=1.5-31.3)$. Moreover, $75 \%, 7 \mid \%$, and $66 \%$ of Thai parents believed that television viewing yielded benefits to children's developments.

Conclusion: Thai children commenced watching television at an early age and the amount of television viewing time increased by age. Most parents had positive perceptions to television viewing. The study found no association between time spent on television viewing ( $\geq 2$ hours per day) and delayed language development at the age of 2 years.

Gender (male) was the only variable associated with delayed language development. 


\section{Background}

Television has become part of children's daily life. However, effect of television viewing to children and adolescents; in terms of health, social interaction, behaviour, attention and development, is inconclusive [1-5]. Television viewing may provoke either positive or negative impact to developments of children [6]. According to the American Academy of Paediatrics (AAP), electronic screens viewing time should not exceed 2 hours per day [7]. These recommendations are based on the assumption that children who spent their time on screen media may spend less time with their parents; and, thus, may be detrimental to their development [8].

On average, school-aged American children spent 2-5 hours per day watching television $[9,10]$. However, data regarding exposure to television in very young children (especially in infants and toddlers who were younger than 2 years) is limited, in particular data from the Asian population. A study from the USA demonstrated that $17 \%$ of 0 - to 11 -month-olds, $48 \%$ of 12 - to 23 -month-olds, and $41 \%$ of $24-$ to 35 -month-olds watched television more than 2 hours per day [11]. Also, a longitudinal study in the USA reported that children aged $11 / 2$ years and $31 / 2$ years spent average of 2.2 and 3.6 hours per day, respectively, watching television [12]. Those studies showed that the AAP recommendations have not been obeyed in the real world [13].

Although, there are a number of studies demonstrated the impact of television viewing to school-age children's development, data in infants and toddlers is limited [6]. Previous published data reported inconclusive effect of television viewing to language development in young children, depending mainly on types of television programmes [6]. Some children's television programmes, where onscreen characters speak directly to the child, actively participate, label objects, contain vocabulary words and their definitions, and provide the child to respond, such as Dora the Explorer, Blue's Clues, Dragon Tales, Arthur and Clifford, may enhance children's language development. On the other hand, some programmes that have loose narrative structure and poor language models such as Sesame Street and Teletubbies were associated with reduced vocabulary in the children [14].

Time spent on television, types of programmes and parental control over child's television viewing may be cultural different between the Asian and the western countries. Recent case-control study in Thailand found the negative relationship between television viewing onset, television viewing time, and language development [15]. However, there is no prospective longitudinal research regarding the association between television viewing and language development and parental perception on television viewing in infants and toddlers in Asian countries. This study was carried out with the aims (a) to study the amount of time spent on television viewing in 6-month-, 1- and 2year-old Thai children; (b) to investigate whether longer time spent on television viewing ( $\geq 2$ hours per day) were associated with delayed language development at the age of 2 years; and (c) to explore parental perceptions on television viewing toward their child's development.

\section{Methods}

\section{Participants and procedures}

The study was a part of the Prospective Cohort Study of Thai Children (PCTC), a community-based longitudinal birth cohort study following up children from birth to 24 years of age. Children who were born during October 2000 and September 2002 at two university-based hospitals (Ramathibodi and Rajavithee Hospitals) in Bangkok, Thailand and their parents were recruited into the study. The study was ethically approved by the National Ethics Committee, the Ministry of Public Health of Thailand, and the Ethics Committees of both hospitals.

Two hundred and sixty children and their parents agreed to participate into the study and signed inform consents. Data regarding amount of time spent on television viewing were collected during face-to-face interview with the parents when the children were 6 months, 1 and 2 years old. The parental perceptions on television viewing were recorded during the telephone interviews. Language development was evaluated when all children were 2 years old, by qualified developmental and behavioural paediatricians. Of the 260 children and parents recruited into the study; 260, 256 and 203 children remained in the study after they were 6 months, 1 and 2 years old; only 220 parents completed the telephone interview. The remaining had either withdrawn from the study because of their inconvenience or loss of contact.

\section{Measurements}

\section{Television viewing}

At the age of 6 months, parents were asked to answer the question "How often did your child was placed in front of the television?" and were asked to classify (their child's television exposure) as "Never" (not at all), "Sometimes" (less than 4 days per week) and "Often" (4 days or more per week). The amount of time spent each day on watching television was not recorded at the age of 6 months. At the age of 1 and 2 years, the parents were asked to answer the question "How many minutes/hours has your child spent on watching television a day?". The amount of time spent on television viewing was then recorded. However, names and types of the television programmes were not documented. 


\section{Assessment of language development}

Assessment of delayed language development was carried out by using standardized instrument, modified Clinical Linguistic Auditory Milestone Scale (CLAMS) [16]. The CLAMS was modified to fit Thai cultures and was translated from English into Thai. All pictures in modified CLAMS depicted the same items as the original CLAMS, except the picture of a dog. The dog picture was administered to children in all regions of the country except in the south, where dog is not a common pet. Therefore, a goat, which is usually seen in most families, was selected to substitute the dog picture. All administrators using the modified CLAMS received training by the developmental and behavioural paediatrician and were supervised during its administration. "Delayed language development" was documented when the child failed all items at the 21 months of age which implied the child was functioning at less than $87.5 \%$ age expectations.

\section{Parental perceptions on television viewing}

Parental perceptions on television viewing were assessed in three main areas of child development: attitude toward cognitive development, attitude toward language development and attitude toward social development. Parents were asked to answer the question: "Do you think watching television would likely enhance or delay or would not affect your child's cognitive/language/social development?". Responses were categorised as positive (television enhances child's development), negative (television delays child's development) and no effect (television has no effect on child's development).

\section{Analyses}

Statistical analyses were carried out with SPSS 11.5 (SPSS, Chicago, IL, USA). Descriptive analyses were used to ascertain the amount of time spent on television viewing and to analyse data on the parental perceptions toward television viewing. Association between delayed language development and time spent on television viewing, as well as other various parameters, were analysed using a multivariate logistic regression model. Odds ratios and 95\% confidence intervals were reported.

\section{Results}

The percentages of children who watched television at the age of 6 months, 1 year and 2 years were 98, 95.3 and 96.7, respectively. Of the 260 six-month-old children; $43.5,54.2$ and $2.3 \%$ were "often", "sometimes" and "never" watched television, respectively. Moreover, 22.4\% of 1-year-old children spent $\geq 2$ hours per day on television viewing, and $38.4 \%$ of 2 -year-old children watched television $\geq 2$ hours per day. The average television viewing time for the 1 - and 2-year-old children was $1.23 \pm 1.42$ and $1.69 \pm 1.56$ hours per day, respectively.

On multivariate analysis, only gender was significantly associated with delayed language development $(\mathrm{OR}=6.9$,
95\% CI $=1.5-31.3)$. There was no association between delayed language development and other variables (maternal education, monthly family income, number of children in family, number of household televisions, television in child's bedroom and time spent on television viewing) (Table 1).

Of the 203 two-year-old children, 16 (7.9\%) had "delayed" language development, and all watched television since they were 6 months old. Also, of the 16 children with delayed language development, 4 spent $\geq 2$ hours per day on television viewing, and 12 children spent $<2$ hours per day on television. Whilst; of the 187 children who had normal language development, 74 spent $\geq 2$ hours per day on television viewing, and 113 children spent $<2$ hours per day on television. There was no association between delayed language development and longer time spent on television viewing ( $\geq 2$ hours per day) $(\mathrm{OR}=0.5,95 \% \mathrm{CI}=0.2-1.6)$ (Table 1$)$.

In addition, 75, 70.9 and $65.5 \%$ of parents who completed the interview believed that television viewing could enhance their children's cognitive, language and social development (Figure 1).

\section{Discussion}

This longitudinal birth cohort study presented data on: (a) the amount of time spent on television viewing in infants and toddlers, (b) the association between time spent on television viewing and language development, and (c) parental perceptions on television viewing toward their children's development.

The definition of "watching television" in this (and other) study has to be carefully evaluated. Watching television in the very young child (especially in the child who is younger than 1 year old) is difficult to evaluate. In this study, we assume that children, who were left to expose to television would be able to learn and understand words and pictures on television; thus, would regard as watching television. In addition, with our limited resources, we were able to record broad frequencies of television viewing for 6 months old children. Although, recording television viewing time with viewing diaries is more reliable than parents' report, it requires high parent's effort and cooperation. The amount of viewing time recorded by parents' self report may tend to be underestimated, and is a more-to-common practice.

According to the AAP, exposure to television should be restricted in children who are younger than 2 years old [7]. However, $98.0 \%$ of 6 -month-old, $95.3 \%$ of 1 -year-old and $96.5 \%$ of 2 -year-old children in Thailand watched television. These are comparable with other studies from different countries where more than $90 \%$ of children younger than 2 years old were reported to watch television 
Table I: Associations between delayed language development at the age of 2 years and various parameters.

\begin{tabular}{|c|c|c|c|}
\hline \multirow[t]{2}{*}{ Parameters } & \multicolumn{2}{|c|}{ Language development at 2 years old } & \multirow{2}{*}{$\begin{array}{l}\text { Odds ratio } \\
(95 \% \mathrm{Cl})\end{array}$} \\
\hline & Normal $(n=187)$ & Delayed $(n=16)$ & \\
\hline \multicolumn{4}{|l|}{ Gender } \\
\hline Male & 94 & 14 & $6.9(1.5-3 \mid .3)$ \\
\hline Female & 93 & 2 & 1.0 \\
\hline \multicolumn{4}{|l|}{ Maternal education } \\
\hline$\leq 12$ years & $|4|$ & 12 & $1.0(0.3-3.2)$ \\
\hline$>12$ years & 46 & 4 & 1.0 \\
\hline \multicolumn{4}{|c|}{ Monthly family income (in Thai baht, IUS $\$=40$ baht) } \\
\hline$\leq \mathbf{5 0 , 0 0 0}$ & 175 & 15 & $0.4(0.05-3.7)$ \\
\hline$>50,000$ & 12 & 1 & 1.0 \\
\hline \multicolumn{4}{|c|}{ Number of children in family } \\
\hline$\leq \mathbf{2}$ & 168 & 15 & $0.6(0.07-4.7)$ \\
\hline$>2$ & 19 & 1 & 1.0 \\
\hline \multicolumn{4}{|c|}{ Number of televisions in households } \\
\hline$\leq 2$ & 150 & 13 & $0.9(0.3-3.5)$ \\
\hline$>2$ & 37 & 3 & 1.0 \\
\hline \multicolumn{4}{|c|}{ Television in child's bedroom } \\
\hline Yes & 123 & 7 & $0.4(0.1-1.1)$ \\
\hline No & 64 & 9 & 1.0 \\
\hline \multicolumn{4}{|c|}{ Time spent on television viewing at 2 years old } \\
\hline$\geq 2$ hours per day & 74 & 4 & $0.5(0.2-1.6)$ \\
\hline$<2$ hours per day & 113 & 12 & 1.0 \\
\hline
\end{tabular}

Adjusted odds ratios with $95 \%$ confidence intervals were calculated using multivariate logistic regression adjusting for all factors presented in the table.
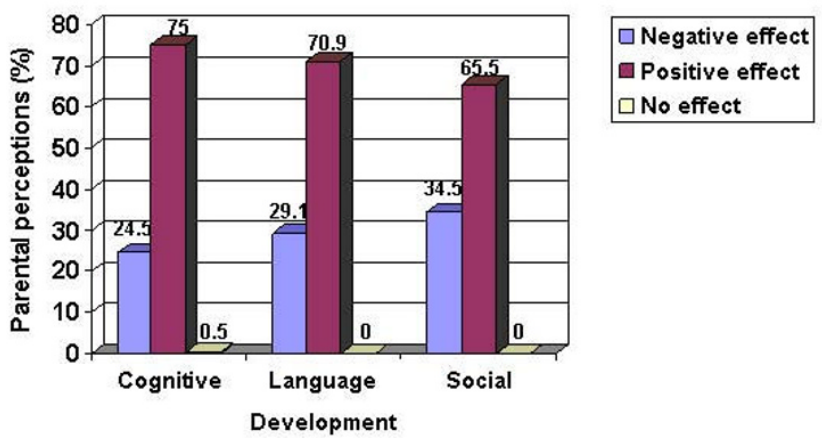

Figure I

Parental perceptions on the effects of television viewing toward children's development. 75, 70.9 and $65.5 \%$ of parents believed that television viewing had positive effect to children's cognitive, language and social development.
[10,17-19]. Findings from our and other studies reflect that the AAP guidelines have not been heeded.

The increased time spent on television viewing was found when the children were older. Time spent on television viewing increased from $1.23 \pm 1.42$ hours per day at the age of 1 year to $1.69 \pm 1.56$ hours per day when the children were 2 years old. A study from the USA also documented the increased time spent on television viewing in children during their first 3 years [11]. However, time spent on television is cultural and socioeconomically dependent, varies amongst families, and is likely to be influenced by habit of parents and other members in the family [20].

One of the intentions of this study was to assess the association between delayed language development and the maximum time spent on television recommended by the AAP [7]. However, only seven two-year-old children followed the AAP guidelines (not watching television). Thus, 
we have analysed the association between delayed language development and time spent on television viewing at $\geq 2$ or $<2$ hours per day. No association between delayed language development at the age of 2 years and time spent on television viewing ( $\geq 2$ hours per day) was found. However, the only 16 children with delayed language development detected in the study may not have been adequately powered to identify any association. In contrast, other study proposed that exposure to television before the age of 3 years could deteriorate children's cognitive development, thus, resulted in lower reading performance in early elementary school [21]. Longer followup (e.g. at the age of 3 or 4 years) should illustrate clearer direction.

Factors responsible for impaired language development are complex and have not been clearly identified. However, evidence has suggested that gender and genetics may involve in these intricate mechanisms. Delayed language development was observed amongst siblings who had family history of language impairment [22]. Furthermore, other studies proposed that boys are more likely to have impaired language development than girls, possibly due to genetics and neurobiological factors [23-25]. Our study, on the multivariate analysis, has confirmed this observation ( $\mathrm{OR}=6.9,95 \% \mathrm{CI}=1.5-31.3)$. The study found no association between maternal education and monthly family income and delayed language development, which inconsistent with other studies [25-27]. This is probably due to our sample population was ascertained through two institutions from certain geographical areas of the country (Bangkok). Therefore, this population may not be representative of the Thai population and might affect the association between delayed language development and socioeconomic status.

Findings from this study showed that $64 \%$ of 2 -year-old children in Thailand had television set in their bedrooms. According to the AAP recommendations, this was not a good practice, as television sets should be removed from children's bedrooms [7]. Again, this recommendation may not be simply applied to the environment and the culture in Thailand (and, probably, other Asian countries), where parents would prefer their child staying in the same room with them until the school age. Furthermore, in many low socioeconomic status families in Thailand, only 1-2 rooms are available in their houses; and that all family members would be forced to stay in the same room.

Regarding types of programmes, although evidence has suggested that educational television programmes may increase school readiness in children $[5,28]$, the benefits of these programmes are questionable in infants [14]. A recent study has suggested that only the infant-directed educational programme with parental co-viewing, not the general educational programme for children, could enhance infant-mother interactions [17]. This type of program with parent co-viewing may improve children's long-term developmental outcome [29]. Meanwhile, adult programmes could provide negative effects to cognitive and language development [30]. Our study did not record types of television programmes watched by the children.

The positive parental perceptions on television viewing toward children's development were demonstrated for the first time in Thailand. Other study in the USA has previously documented similar findings [19]. Parents believed that screening media (e.g. television, DVD, video), if appropriately used, are educational and useful to their child's brain development [19]. Those positive parental attitudes on television viewing may be influenced by television programmes, which have claimed to have educational value for children. However, positive parental perceptions may be deleterious to children, if parents do not carefully concern about the types of programme. A number of research demonstrated detrimental impact of the television viewing to cognitive and social development, if the content in the programmes was not appropriated to children $[2,12]$. Therefore, parents should closely monitor contents of the programmes and should decide appropriately which television programmes are useful for their child.

In this study, modified CLAMS was used to identify children with delayed language development. Different cultures may also limit the use of original CLAMS in identifying children with delayed language development. We have also concerned that administering only the items at 21 months of age may affect a number of children with delayed language development reported in this study.

\section{Conclusion}

This is the first prospective longitudinal report in Thailand where the amount of time spent on television viewing, as well as the association between television viewing and language development and parental perceptions on television viewing, were studied. In Thailand, most children (> $95 \%$ ) exposed to television at the very young age (6 months or less). However, this did not associate with delayed language development at the age of 2 years. Gender (male) was the only significant factor associated with delayed language development $(\mathrm{OR}=6.9,95 \% \mathrm{CI}=1.5-$ 31.3). Parents in Thailand expressed their positive perceptions in the value of television viewing to their child's development. Appropriate information based on our findings should be disseminated to paediatricians and parents in order to help them understand the risks and benefits of television viewing. 


\section{Competing interests}

The authors declare that they have no competing interests.

\section{Authors' contributions}

NR conceived and designed the study, supervised all the work related to the study and edited the manuscript. JC collected, analysed the data, wrote, and edited the manuscript. LM, UU and CC involved in designing, analyzing data and supervised the study. SK collected and analysed data and involved in drafting manuscript. All authors read and approved the final manuscript.

\section{Acknowledgements}

The research was financially supported by the Thailand Research Fund, The Health System Research Institute, The Ministry of Public Health of Thailand, WHO and The Faculty of Medicine Ramathibodi Hospital. We are very grateful to Dr Unchalee and Mr Scott Lodin who proofread the manuscript.

\section{References}

I. Anderson DR, Huston AC, Schmitt KL, Linebarger DL, Wright JC: Early childhood television viewing and adolescent behavior: the recontact study. Monogr Soc Res Child Dev 2001, 66:I-I47.

2. Bickham DS, Rich M: Is television viewing associated with social isolation? Roles of exposure time, viewing context, and violent content. Arch Pediatr Adolesc Med 2006, I 60:387-392.

3. Hancox RJ, Milne BJ, Poulton R: Association between child and adolescent television viewing and adult health: a longitudinal birth cohort study. Lancet 2004, 364:257-262.

4. Hancox RJ, Milne BJ, Poulton R: Association of television viewing during childhood with poor educational achievement. Arch Pediatr Adolesc Med 2005, I59:614-618.

5. Wright JC, Huston AC, Murphy KC, St Peters M, Pinon M, Scantlin R, et al:: The relations of early television viewing to school readiness and vocabulary of children from low-income families: the early window project. Child Dev 2001, 72:1347-1366.

6. Anderson DR, Pempek TA: Television and very young children. The American Behavioral Scientist 2005, 48:505-522.

7. American Academy of Pediatrics CoPE: Children, adolescents, and television. Pediatrics 200I, 107:423-426.

8. Vandewater EA, Bickham DS, Lee JH: Time well spent? Relating television use to children's free-time activities. Pediatrics 2006, I I:el8I-el9|.

9. Kaiser Family Foundation: Generation M: Media use in the lives of 8-18 year-olds CA: Kaiser Family Foundation; 2005.

10. Rideout VJ, Hamel E: The media family: Electronic media in the lives of infants, toddlers, preschoolers, and their parents CA: Kaiser Family Foundation; 2006

II. Certain LK, Kahn RS: Prevalence, correlates, and trajectory of television viewing among infants and toddlers. Pediatrics 2002, 1 09:634-642.

12. Christakis DA, Zimmerman FJ, DiGiuseppe DL, McCarty CA: Early television exposure and subsequent attentional problems in children. Pediatrics 2004, I I 3:708-7| 3.

13. Strasburger VC: First do no harm: Why have parents and pediatricians missed the boat on children and media. Journal of Pediatrics 2007, I 5 I:334-336.

14. Linebarger DL, Walker D: Infants' and toddlers' television viewing and language outcomes. The American Behavioral Scientist 2005, 48:624-645

15. Chonchaiya W, Pruksananonda C: Television viewing associates with delayed language development. Acta Paediatrica 2008, 97:977-982.

16. Pittock ST, Juhn YJ, Adegbenro A, Voigt RG: Ease of administration of the cognitive adaptive test/clinical linguistic and auditory milestone scale (CAT/CLAMS) during pediatric wellchild visits. Clin Pediatr (Phila) 2002, 41:397-403.

17. Mendelsohn AL, Berkule SB, Tomopoulos S, Tamis-LeMonda CS, Huberman HS, Alvir J, et al:: Infant television and video exposure associated with limited parent-child verbal interactions in low socioeconomic status households. Arch Pediatr Adolesc Med 2008, I62:4II-4I7.

18. Weber DS, Singer DG: The media habits of infants and toddlers: findings from a parent survey. Zero to Three 2004, 25:30-36.

19. Zimmerman FJ, Christakis DA, Meltzoff AN: Television and DVD/ video viewing in children younger than 2 years. Archives of Pediatrics and Adolescent Medicine 2007, I 6 I:473-479.

20. Yalcin SS, Tugrul B, Nacar N, Tuncer M, Yurdakok K: Factors that affect television viewing time in preschool and primary schoolchildren. Pediatrics International 2002, 44:622-627.

21. Zimmerman FJ, Christakis DA: Children's television viewing and cognitive outcomes: a longitudinal analysis of national data. Arch Pediatr Adolesc Med 2005, I 59:619-625.

22. Chuthapisith J, Ruangdaraganon N, Sombuntham T, Roongpraiwan R: Language development among the siblings of children with autistic spectrum disorder. Autism 2007, I I: | 49 - 160.

23. Zubrick SR, Taylor CL, Rice ML, Slegers DW: Late language emergence at $\mathbf{2 4}$ months: an epidemiological study of prevalence, predictors, and covariates. J Speech Lang Hear Res 2007, 50:I562-I592.

24. Nelson HD, Nygren P, Walker M, Panoscha R: Screening for speech and language delay in preschool children: systematic evidence review for the US Preventive Services Task Force. Pediatrics 2006, I I 7:e298-e319.

25. Reilly S, Wake M, Bavin EL, Prior M, Williams J, Bretherton L, et al:: Predicting language at $\mathbf{2}$ years of age: a prospective community study. Pediatrics 2007, I 20:e I44 I-e I 449.

26. Bradley RH, Corwyn RF: Socioeconomic status and child development. Annu Rev Psychol 2002, 53:371-399.

27. Tomblin JB, Hardy JC, Hein HA: Predicting poor-communication status in preschool children using risk factors present at birth. J Speech Hear Res I99I, 34:1096-I I05.

28. Rice ML, Huston AC, Truglio R, Wright J: Words from Sesame Street - Learning Vocabulary While Viewing. Developmental Psychology 1990, 26:421-428.

29. Tamis-LeMonda CS, Bornstein MH, Baumwell L: Maternal responsiveness and children's achievement of language milestones. Child Dev 2001, 72:748-767.

30. Schmidt ME, Pempek TA, Kirkorian HL, Lund AF, Anderson DR: The effects of background television on the toy play behavior of very young children. Child Development 2008, 79:। |37-I।5।.

\section{Pre-publication history}

The pre-publication history for this paper can be accessed here:

http://www.biomedcentral.com/1471-2431/9/34/prepub

Publish with Bio Med Central and every scientist can read your work free of charge

"BioMed Central will be the most significant development for disseminating the results of biomedical research in our lifetime. "

Sir Paul Nurse, Cancer Research UK

Your research papers will be:

- available free of charge to the entire biomedical community

- peer reviewed and published immediately upon acceptance

- cited in PubMed and archived on PubMed Central

- yours - you keep the copyright 